\title{
JACK LONDON: BIOLOGISMO Y LITERATURA PERRUNA ${ }^{1}$
}

Jack London: biologism and canine literature

\author{
Bernardo Subercaseaux $\left(^{*}\right)$
}

\section{RESUMEN}

El artículo se propone examinar el trasfondo biológico y darwinista de la obra de London. Examina también el imaginario sobre la naturaleza y el mundo animal en la cultura norteamericana de comienzos de siglo. Muestra la incidencia de la teoría evolucionista en la trama y en la estrategia compositiva de cuentos y novelas del autor, destacando, empero, la autosuficiencia y autonomía estética de sus narraciones. Examina y reflexiona sobre el pensar literario y el pensar argumentativo y racional.

\section{Palabras clave:}

Evolución, instintos, autosuficiencia estética, lobos, perros.

\footnotetext{
(*) Departamento de Literatura Facultad de Filosofía y Humanidades, Universidad de Chile. Santiago, Chile. Correo electrónico: besuberc@uchile.cl ${ }^{1}$ Artículo realizado en el marco del Proyecto N 1100148 del Fondo Nacional de Desarrollo Científico y Tecnológico
(FONDECYT), titulado: "Representaciones e imaginarios perrunos".

Artículo recibido el 30 de enero de 2013. Aceptado el 2 de abril de 2013.
} 


\begin{abstract}
The article proposes to examine the biological and Darwinian background of London's work. It also examines the imaginary about the nature and the animal world in the North American culture of the beginning of century. It shows the influence of the evolutionary theory in the plot and in the strategy composite of stories and novels of the author, emphasizing, however, the self-sufficiency and aesthetic autonomy of his stories. It examines and thinks on to think literary and to think argumentative and rationally.
\end{abstract}

Keywords:

Evolution, instincts, aesthetic self-sufficiency, wolves, dogs.

\title{
INTRODUCCIÓN
}

En 1897, un joven californiano de 21 años, con aspecto de actor de cine, pero pobre como una rata, iniciaba junto con su cuñado una aventura: partían a Alaska en busca de oro, al río Yukon y a uno de sus afluentes, el Klondike. Cruzarían parajes nevados y desérticos, desafiando el invierno ártico de abetos muertos, atravesando ríos torrentosos y asediados en las noches por lobos hambrientos, por vientos gélidos y por un largo y profundo silencio blanco. Se trata de un joven que -al igual que El Pibe de Chaplin- vino al mundo en calidad de hijo indeseado, un niño que su madre entregó en crianza a una nodriza y ex esclava negra de Oakland; un adolescente que se lavó los dientes por primera vez a los 19 años, y que, como el Chaplin de Tiempos Modernos, experimentó la industrialización y el fordismo trabajando hasta 16 horas diarias en una fábrica de conservas, quedando para siempre con una fobia a la rutina y al ruido de las máquinas; un joven con ideas socialistas, que con el afán de huir de la miseria y de trabajos esclavizantes partió - como el protagonista de La Quimera de Oro- a la recóndita Alaska, embarcándose, como lo hicieron en ese año miles de aventureros, en el gold rush de Klondike y en el sueño de una riqueza rápida. El joven socialista que partía en búsqueda de oro, además de carpas, trineo, frazadas e instrumentos de minería, llevaba entre sus pertrechos tres o cuatro libros, entre ellos El origen de 
las especies (1859) de Charles Darwin ${ }^{2}$. Aun cuando carecía de educación formal, Jack London (que así se llamaba el joven) ya situaba en el panteón de sus héroes a Herbert Spencer y Charles Darwin. Después de un año de haber iniciado esta aventura, London regresaba a San Francisco con escorbuto, sin dinero y sin oro, pero con un bagaje de experiencias darwinianas -experiencias de sí mismo, de los animales y de la naturaleza- que serían fundamentales para algunas de sus obras más significativas ("It was in the Klondike that I found myself. There nobody talks. Everybody thinks. You get your true perspective. I got mine"3). A comienzos del siglo XX, gracias a sus primeras novelas, London alcanzó un éxito extraordinario, con royalties que le permitieron adquirir un yate (otro de sus grandes temas fue la Polinesia y los mares del sur) y un rancho en California, en el que vivió los últimos años de su (mala y buena) vida, hasta fallecer en 1916, con solo cuarenta años.

En su prolífica y variada obra -20 novelas y más de 200 cuentos- entre otros temas, London abordó la relación entre humanos y animales, o entre distintos tipos de animales (lobos y perros), siempre en un clima de aventura. Se trata, básicamente, de su obra más conocida, de los cuentos "The son of the wolf" (1899), "Batard"(1902) y "Love of life" (1907) y de sus novelas, ya clásicas, The call of the wild (1903) (El llamado de la selva) y White fang (1906) (Colmillo Blanco). Son textos en que la energía narrativa productiviza la adaptación al medio ambiente y la sobrevivencia del más apto, tanto de animales humanos como no humanos. Narraciones que, con un trasfondo evolucionista de cuño darwiniano, perfilan imaginarios perrunos tematizando lo atávico, la herencia, los instintos, la domesticación y la lucha por subsistir.

Nos proponemos examinar estos temas desde el punto de vista del darwinismo y del neodarwinismo. Tenemos en cuenta, además de los escritos del propio Darwin, reflexiones del etólogo Karl Lorenz, del paleontólogo Stephen Jay Gould, y un ensayo de tono evolucionista de José Ortega y Gasset, así como las investigaciones de Julieta Troncoso, Roberto Palacio y Enrique Zerda, coautores de Bases biológicas del comportamiento animal y humano ${ }^{4}$. Abordaremos, también, el imaginario sobre la naturaleza y el mundo animal en la cultura norteamericana. Mostraremos, además, cómo el trasfondo evolucionista incidió en la trama, en la peripecia y en

\footnotetext{
${ }^{2}$ Haley, James L. Wolf. The lives of Jack London. New York: Basic Books, 2010.

${ }^{3}$ London, Jack." Eight Factors of Literary Success“. The Silhoutte, February, 1917. En The portable Jack London. Earle Labor (ed.). Nueva York: Penguin Books, 1994: 512.

${ }^{4}$ (Editor Enrique Zerda). Bogotá: Universidad Nacional de Colombia, 2010.
} 
la estrategia compositiva de los cuentos y novelas mencionadas, sin duda las más leídas de su producción. Nos interesa, finalmente, examinar su pensar literario respecto a la condición animal y la condición humana.

\section{INSTINTOS Y DOMESTICACIÓN}

Para Darwin, el hombre, los animales y todas las criaturas vivas han evolucionado desde modos de vida primitivos, a través de variaciones que resultan funcionales para la preservación de cada especie. Las mudanzas favorables, que obedecen a la adaptación a nuevas condiciones de vida, se conservan en el sistema reproductor, mientras que las perjudiciales se desechan. Concebidos biológicamente en una perspectiva evolucionista, los instintos son pautas de comportamiento innatas o heredadas, que desempeñan en este proceso un rol fundamental. Conforman una especie de inteligencia rudimentaria internalizada en el sistema nervioso; son pulsiones que no implican aprendizaje, que dirigen $\mathrm{u}$ orientan a los seres vivos en sus acciones, operando con propósitos de conservación y supervivencia, sin que intervenga la voluntad. Son comportamientos -tales como el instinto sexual o el agresivo- que no requieren experiencia previa para manifestarse. Según las interacciones que se dan con el entorno pueden, sin embargo, producirse cambios: ciertos instintos disminuyen y otros - en la medida que son favorables- pasan a ser hereditarios. Los instintos, tal como las estructuras corporales, se incrementan con el uso o hábito y se pierden o desaparecen con el desuso, eso es -según Darwin- lo que ha sucedido con los animales domesticados y también con la especie humana ${ }^{5}$.

A partir de investigaciones sobre las bases neurofisiológicas del aprendizaje motor, los neodarwinistas afirman, complementando a Darwin, que el aprendizaje y cualquier comportamiento nuevo, como los que se dan por ejemplo en los perros domesticados, están siempre inscritos - por innovadores que sean-en un repertorio de conductas innatas, en pautas de comportamiento preexistentes. Aprender, explica Julieta Troncoso, "significa modificar los circuitos neuronales implicados en un comportamiento determinado. Pero esos circuitos existen previamente a la experiencia” del aprendizaje ${ }^{6}$. Eso permitiría que en el perro domesticado que

\footnotetext{
${ }^{5}$ Darwin, Charles. El origen de las especies (1859) y El origen del hombre (1871). En Robert Jastrow. Charles Darwin: Textos fundamentales. Barcelona: Altaya, 1993:152-158.

${ }^{6}$ Troncoso, Julieta. "El concepto de Comportamiento Aprendido". En Enrique Zerda (ed.). Bases biológicas del Comportamiento Animal y Humano. Bogotá: Editorial Universidad Nacional de Colombia (2010): 69-79.
} 
aprendió a ser carińoso y a jugar con los nińos, se produzca de pronto una reversa, y reaparezca el instinto agresivo: lo atávico que subyace en la memoria de la especie.

José Ortega y Gasset proyecta algunas de estas ideas en un ensayo sobre la caza mayor unipersonal. Establece una diferencia entre el hombre y el animal. Mientras al primero la vida se le da vacía, y tiene que llenarla con sus actos y voluntad, al animal la vida se le da con un repertorio invariable de conducta, puesto que los instintos le dan ya resuelto lo que tiene que hacer y lo que debe evitar ${ }^{7}$. Señala que el hombre, en cambio, perdió el sistema de sus instintos y solo le quedan residuos o muñones que son "incapaces de imponerle un plan de comportamiento".

Según Ortega la caza está presente en todo el reino animal: el gato caza ratones, el león antílopes, los patos babosas y gusanos, las avispas orugas y gorgojos. Cada especie cazadora tiene instintos predatorios específicos y cada especie cazada cuenta a su vez con instintos defensivos (también específicos) que dificultan su captura. El animal doméstico conserva, como el hombre, -dice Ortega- solo muñones de esos instintos; desde un punto de vista biológico tanto el uno como el otro han mitigado sus conductas innatas, son, biológicamente hablando, animales degenerados. Sin embargo, esos muñones que yacen agazapados en el fondo genético de la especie, de repente reaparecen: es el caso del perro domesticado que reduce ciertos instintos de sus antepasados (la depredación, la agresión y el liderazgo), ese perro que a pesar de recibir cada día su merienda, cuando encuentra un hueso lo entierra como si fuese todavía un perro o un lobo hambriento de la manada. Es también el caso del ser humano que restablece, cuchillo en mano, su dominio, o que asesina a su pareja por miedo a perderla, dando pie a pulsiones ancestrales por defender el territorio propio y la posibilidad de reproducción. Esta reaparición de lo atávico (que en biología apunta a la memoria genética de la especie) es lo que ocurre, según Ortega, en el cazador solitario.

El etólogo Konrad Lorenz formula en otros términos la misma distinción que Ortega. En el animal salvaje -afirma- todos los impulsos instintivos están regulados de tal forma "que tienen que contribuir al bienestar de la especie a

${ }^{7}$ Ortega y Gasset, José. prólogo a Veinte años de caza mayor. Por el Conde de Yebes. Madrid: Espasa Calpe, 1943. Reproducido en Ortega y Gasset, José. Sobre la caza, los toros y el toreo. Madrid: Alianza, 1960. 
que pertenece. En su recinto vital no hay conflicto alguno entre apetencias naturales y un deber ser, "todo impulso interior (en el animal salvaje) es bueno". Se trata de una sincronía que Lorenz califica de paradisíaca, en la medida que no hay dilema moral, sincronía que se habría "perdido en el hombre" ${ }^{8}$. En el ser humano el lenguaje y el pensamiento racional hicieron posible un acervo común de la especie, un enculturamiento y una ética social a partir de las cuales no cabe abandonarse ciegamente a sus instintos. Sobre todo considerando que los instintos son impulsos de acción y reacción espontáneos, y, por lo mismo, temibles. "Las apetencias naturales - dice Lorenz- no concuerdan ya con los condicionamientos de la cultura en que se encuentra el hombre gracias a los logros de su mente". En este proceso de enculturamiento sitúan los evolucionistas a la domesticación de los animales (humanos y no humanos). Sin embargo, hay al respecto distintas posiciones: para algunos científicos el hombre es solo un mono desnudo que habla'; para otros la especie humana se habría elevado en su evolución sobre los animales. En esta última perspectiva, autores como Lorenz proponen que el enculturamiento habría distanciado al hombre de la mera evolución biológica. London, como veremos, se ubica por lo general en la primera posición, pero a veces, en su ficción se desplaza a la segunda. Como estudioso de los animales, Lorenz, sin embargo, nos previene acerca de la mente y la racionalidad humana, las que no siempre están "enculturadas", menciona como ejemplos a la bomba atómica y a Hiroshima. Los sueños de la razón -como ya lo advirtió Goya a fines del siglo XVIII- producen monstruos.

El cazador solitario que avanza lenta y dificultosamente entre arbustos y montículos, tropezando aquí y allá, ese cazador que con obstinada paciencia está focalizado en visualizar a su presa para dar cuenta de ella, se iguala al cazador del paleolítico y al animal depredador, a la araña que se mantiene inmóvil en su tela, a la pantera expectante en su emboscada. Son seres vivos que operan movidos por instintos ancestrales y primitivos. Ortega que es filósofo y no etólogo, señala, pensando probablemente en los perros y en los gatos caseros, que la "domesticación desanimaliza parcialmente a la bestias y las humaniza”. Dentro de la misma lógica - pero en sentido contrario- la caza mayor animalizaría al hombre, produciéndose en él una reversa (reversa que es frecuente en los relatos de London). "En la

\footnotetext{
${ }^{8}$ Loren, Konrad. Cuando el hombre encontró al perro. Barcelona: Tusquets, 1875.

${ }^{9}$ Morris, Desmond. zoólogo inglés, autor de The naked ape (1967) y The human zoo (1969).
} 
caza como deporte - dice Ortega- hay una libérrima renuncia del hombre a la supremacía de su humanidad". Animal humano y animal no humano se igualan, activados por sus respectivos e innatos instintos, unos para cazar y otros para no ser cazados. Se retorna así a las etapas ancestrales de la especie, en que los humanos vivían en cuevas desde las que salían a recolectar alimentos o a cazar, compitiendo con otros animales por recursos. Como afirma Ortega, la caza es para el hombre una suerte "de vacaciones de la humanidad".

\section{AGRESIVIDAD}

El instinto agresor es un comportamiento que apunta a la sobrevivencia del más apto $^{10}$, una forma de competencia por recursos, en que un animal excluye a otros en la disputa por alimentos, refugio o pareja ${ }^{11}$. Entre los animales, la agresión no resulta negativa puesto que se trata de un instinto necesario, que en una perspectiva evolucionista se encuadra en la sobrevivencia del más apto y en la selección natural. Enrique Zerda distingue varias modalidades de comportamiento agresivo en los animales: la agresión territorial, la agresión de dominancia, la agresión antipredatoria y la agresión xenofóbica, estimulada por la presencia de un extraño (todas ellas presentes en los relatos de Jack London). Los etólogos plantean incluso la hipótesis de hormonas de agresión. Roberto Palacio sostiene que los mecanismos de agresión en el hombre no difieren radicalmente de los mecanismos de agresión que se encuentran en los animales ${ }^{12}$ : son comportamientos que están en la memoria genética tanto de los animales humanos como de los no humanos, especies que, miradas en el tiempo largo de la evolución, nacieron recién ayer y son, según el paleontólogo Stephen Jay Gould, solo "una minúscula brizna...en el enorme árbol de la vida"13. Nuestra supervivencia -señala el biólogo Enrique Zerda- depende "como la de todos los animales, de la habilidad para obtener alimento y refugio, encontrar pareja, producir descendencia”, protegerse de las amenazas externas "y evitar depredadores"14. Paralelamente al instinto agresivo, el neodarwinismo ha planteado la presencia en la evolución del instinto altruista

\footnotetext{
${ }^{10}$ Lorenz, Karl. Sobre la agresión, el pretendido mal. Madrid: Siglo XXI, 1971.

${ }^{11}$ Zerda, Enrique. "Bases biológicas del comportamiento agresivo". En Enrique Zerda (ed.). Bases biológicas del comportamiento animal y humano, op. cit.

${ }^{12}$ Palacio, Roberto. "Bases biológicas del comportamiento agresivo" en Bases biológicas del comportamiento animal y humano, op. cit.

${ }^{13}$ Jay Gould, Stephen. Ever Since Darwin: Reflections in Natural History. Nueva York: Norton \& Company, 1977.

${ }^{14}$ Zerda, Enrique. Introducción. Bases biológicas del comportamiento animal y humano, op. cit.
} 
y solidario, tanto en la especie humana como en los animales e insectos sociales, sobre todo en las abejas y las hormigas.

Según Karl Lorenz la agresión es un comportamiento que se dispara en el vacío, en circunstancias que pueden estar o no estar presentes los estímulos o las situaciones que generalmente incitan a estas conductas. Son mecanismos pulsionales innatos que están más allá y más acá de todo tipo de consideraciones éticas. "La agresión humana -afirma Roberto Palacio- es el producto de un impulso interno que puede desencadenarse independientemente de que exista o no un estímulo externo, capaz de provocar dicha conducta" 15 . Esta agresión ancestral y gratuita, en la medida que no tiene causas inmediatas, es la que está presente en el cuento "Batard" de London; la consideración biologista de la misma -más allá de toda consideración ética- incide en la perspectiva neutral que asume el narrador. Por otra parte, la neurofisiología ha demostrado que en los humanos el comportamiento agresivo es producto de estimulaciones originadas en los diferentes sistemas y zonas subcorticales del cerebro, en las que se da una interacción entre las neurosecreciones, las hormonas y el sistema límbico.

Otra línea de investigación y reflexión respecto al instinto agresivo es la que estudia el caso de los niños ferales, esos niños que fueron abandonados por sus padres y criados en guaridas de lobos o por manadas de perros (la bibliografía especializada ha documentado más de una centena de casos). Son niños que adoptan modalidades de locomoción y comportamiento agresivo propias de los animales que los cobijaron, y que una vez trasladados al entorno humano requieren de un largo proceso de readaptación, no siempre exitoso ${ }^{16}$. Los niños ferales revelan la capacidad de adaptación de la especie humana y la incidencia del entorno en el sistema de instintos que desarrolla un pequeño ser humano criado por animales, lo que de paso refuerza la hipótesis del fondo común y la proximidad de ambas especies.

\footnotetext{
${ }_{15}$ Palacio, Roberto. "Bases biológicas del comportamiento agresivo". En Bases biológicas del comportamiento animal y humano, op.cit., 174.

${ }^{16}$ Malson, Lucien y Itar, Jean M. G. Les enfants sauvages: mythe et réalité. Paris: Union générale d’éditions, 1964; Candland, Douglas K. Feral children and clever animals: Reflections on Human Nature. London: Oxford University Press, 1993; Newton, Michael. Savage Girls and Wild Boys: a history of feral children. Nueva York: Picador, 2004; Bossa, Jorge Enrique. "Niños ferales y el debate sobre la naturaleza humana". En Bases biológicas del comportamiento animal y humano, op. cit.
} 
Cabe señalar que si bien casi todas las ideas evolucionistas que hemos presentado (frecuentes algunas en la literatura naturalista de la época), están en el trasfondo de la narrativa de Jack London, en ningún caso podemos pensar que sus creaciones son una demostración de esas ideas, y que sus novelas y cuentos serían en consecuencia obras de tesis. Nada más alejado de la realidad. El pensar evolucionista sobre las relaciones entre lobos, perros y humanos alimenta y está presente en la ficción de London, pero siempre subsumido en una narrativa de enorme potencia literaria, en que la representación imaginaria en trance de ocurrir adquiere vida propia y todo lo que se describe está allí ante nuestros ojos, aconteciendo a través de la magia de la palabra en una literatura enaltecida por las vivencias biográficas del autor y por una pluma notable (particularmente cuando se lo lee en inglés).

\section{NATURALEZA Y MUNDO ANIMAL}

El imaginario de los animales y de la naturaleza ha estado desde siempre presente en la cultura norteamericana, tanto en la tradicional como en la contemporánea. Waldo Ralf Emerson (1803-1882), en Nature (1836), instala un pensamiento trascendentalista a partir de la naturaleza, y, más tarde, su seguidor Henri David Thoreau (1817-1867), escribe Walden, the life in the Woods (1854), ensayo en que el espacio natural y los animales forman parte de la identidad geográfica, social y cultural del país del norte, constituyendo, más que un afuera, una alteridad significativa para la autopercepción del yo. Otros autores clásicos como Walt Whitman (1819-1892) y Emily Dickinson (1830-1886) tematizan la naturaleza o los animales como ingredientes en la construcción del sujeto norteamericano. La variedad de flora, fauna, climas y geografía del país y sus paisajes infinitos estimularon la vida al aire libre en todos los sectores de la sociedad. La pesca, la caza y el camping son, como actividades masivas, un invento estadunidense, también la tenencia de mascotas.

En la primera década del siglo XX, cuando se publican las primeras obras de Jack London, se instaura - por iniciativa y bajo el mandato del Presidente Teodoro Roosevelt (1901-1909) - un sistema de parques y reservas nacionales al amparo de leyes de conservación ambiental y forestal, programa que abarcó más de un millón de hectáreas. Considerado un icono de la personalidad yanqui, Roosvelt fue naturalista, explorador, políglota, escritor, deportista y cazador de animales 
(también de países propiciando la política del "Big stick"). Ejerciendo como Presidente recorrió a caballo el parque Yosemite en California, en compañía de John Muir, padre del ecologismo y fundador del Sierra Club. Luego de dejar la presidencia, Roosevelt realizó una expedición al Amazonas, donde un afluente lleva su nombre. En ejercicio de la primera magistratura participó en la "guerra de los naturalistas" (en periódicos y revistas de la época), apadrinó a los científicos contra los llamados "nature fakers" ("falsificadores de la naturaleza y del mundo animal"), entre los que se mencionaba a Jack London, a quien en 1907 el propio Roosevelt, a propósito de su novela White Fang, lo calificó de mistificador del mundo animal y de "amateur" en asuntos de la naturaleza.

¿Cómo y por qué se produjo esta polémica? La naturaleza -incluyendo el mundo animal-, no es solo un espacio objetivo sino que también es subjetivo, en cuanto es un constructo social, un espacio que se politiza en la medida que implica a la imaginación, a proyectos, a utopías y símbolos. Hacia fines del siglo XIX fueron muy populares en Estados Unidos y Canadá las novelas del mundo salvaje, los libros sobre animales para niños y las guías de la naturaleza. Uno de los autores e ilustradores de más éxito fue el canadiense Ernest Thompson Seton (1860-1946), autor de más de 40 libros y miles de ilustraciones sobre el mundo animal. Seton, en Wild animals I have known (1898), presentaba una visión de los animales especialmente de los lobos- como seres inteligentes, altruistas y con valores en ocasiones superiores a los de los seres humanos. El relato testimonial "Lobo, King of the currumpow", narraba cómo Seton, que había sido contratado como cazador de lobos, fue cautivado por la inteligencia y lealtad del jefe de la manada, y se transformó desde entonces en un decidido conservacionista y defensor de los animales. Creador del "Woodcraft Movement" y precursor del movimiento de Boys Scouts, sus obras y las de otros autores como William J. Long, fueron calificadas de "prensa amarilla y sensacionalista" por naturalistas y científicos ${ }^{17}$. Se les criticaba que presentaban a los animales con trazos humanos, como seres inteligentes y morales, a los que se les atribuía sicología y razonamiento más allá de lo que indicaba la evidencia científica de la época, según la cual los animales solo poseían instintos. De la obra de Jack London se llegó a decir que sus perros

\footnotetext{
${ }_{17}$ Dancer, Andrea. "Ernest Thompson Seton and the Canadian Wilderness Imaginary: the realistic Illusion of nature". En Kamila Vrakova y Christopher Koy (eds.). Dream, Imagination and Reality in Literature, en South Bohemian AngloAmerican Studies 1. Checoslovaquia, 2006.
} 
y lobos no eran animales sino seres humanos revestidos de piel ("men in fur") ${ }^{18}$. En la polémica unos concebían a la naturaleza y al mundo animal como exterior e inferior a lo humano, como una instancia de recreación y alimento en pro de la especie, y otros como una utopía en que la naturaleza y los animales eran parte integral de lo humano y de la construcción de sujeto (según Seton "wilderness define man and not the other way around") ${ }^{19}$. En base a sus observaciones, el escritor canadiense planteaba que el comportamiento animal debía ser un modelo para el comportamiento social, un ejemplo para promover "una sociedad sin guerras, descentralizada y más humilde” ${ }^{20}$.

Jack London en un artículo de 1908 respondió a las acusaciones del Presidente Roosevelt y del científico John Burroughs. Empezaba explicando su silencio: "cuando hay una histeria periodística sobre un tema -decía- más vale subirse a un árbol y esperar que se calme la tormenta”. Rebatió los ataques de que había sido objeto, señalando que siempre en sus relatos había sido cuidadoso en hacer coincidir lo representado con los hechos de la evolución. Con respecto a White fang, señaló que el Presidente la había leído mal; defendió la idea de que los animales no son solo autómatas que actúan por mecanismos reflejos, sino que también hay en ellos emociones, memoria y un razonamiento rudimentario ante ciertas situaciones concretas. La visión de que el ser humano es el único animal capaz de razonar, es -dijo- anticuada, homocéntrica e ignora los hechos de la evolución. Discute, además, la idea de que hay un abismo entre el animal hombre y los otros animales. "Compartir el reino animal es para el señor Burroughs tan repugnante como era compartir la teoría heliocéntrica para los monjes que presionaron a Galileo para que se retractara de sus descubrimientos"... "usted no debe negar a sus parientes, los animales" -le dice al señor Burroughs- (y de paso al Presidente), "la historia de ellos es también su historia, y si usted los expulsa al fondo del abismo, al fondo del abismo va usted también. Lo que repudia y niega en ellos usted repudia también en usted"21.

De alguna manera el llamado de atención a la soberbia humana que hace London en 1908, coincide con la reflexión filosófica actual que hace el posthumanismo

\footnotetext{
${ }^{18}$ Lutt, Ralh H. The Nature Fakers: wildlife, Science \& sentiment. Virginia: University Press, 2001.

${ }^{19}$ Dancer, Andrea. "Ernest Thompson Seton and the Canadian Wilderness Imaginary", op. cit.

${ }^{20}$ Dancer, Andrea. "Ernest Thompson Steton and the Canadian Wilderness Imaginary", op. cit.

${ }^{21}$ London, Jack. "The other animals" incluido en Revolution and Other Essays. New York: McMillan, 1909.
} 
(como también la etología) sobre la naturaleza, el ser humano y los animales.

\section{LOBOS Y PERROS}

El imaginario perruno en la obra de London está marcado por su antecesor biológico: el lobo (canis lupus). Son lobos o descendientes de lobos, o perros (canis lupus familiaris) en que reaparecen los instintos lobeznos, la mayoría de los protagonistas de sus relatos y novelas de animales. El lobo simboliza la libertad, la vida animal desnuda y a la intemperie, es el habitante de un espacio en que no tienen presencia ni los disciplinamientos del Estado ni la forma en que estaba organizada la sociedad de la época. Un espacio abierto y sin fronteras, que para el crítico socialista con simpatías anarquistas que fue London, resultaba sumamente atractivo, una naturaleza donde -como lo dice en varias de sus cartas- se sentía viviendo a plenitud. No es casual que la mejor biografía del autor lo identifique como un "Lobo" (Wolf. The lives of Jack London, de James Haley) 22. Por otra parte, los lobos y los perros estaban ya instalados en la literatura norteamericana, sobre todo a partir de la obra de Seton. London, en su aventura del Yukon, tuvo una estrecha relación con ellos. Son ingredientes que en un ambiente en que predominó el determinismo positivista en las ideas, y el naturalismo en la literatura, van a incidir en los que consideramos sus cuentos más logrados.

“The son of the wolf" (1898) es el relato que da título a su primer libro, publicado en 1900. "Batard" (1902) fue el cuento que lo incitó - dice London- a escribir The call of the wild (1903), para redimir la visión algo negativa de los perros presente en ese relato. "The love of life" (1907) es sin duda uno de sus cuentos más notables, cuento que según las Memorias de la mujer de Lenin, éste -en sus últimos díaspedía que se lo leyeran una y otra $\mathrm{vez}^{23}$. En los tres relatos se diluyen y vuelven fluidas las fronteras entre hombre y animal; entre exploradores, lobos y perros, unos y otros actúan por instintos y son lo que son producto de su adaptación al medio -la zona del Yukon- y a la herencia de sus antepasados.

En el primer relato: "Cogote Mackenzie", el personaje, es un "hijo del lobo", apodo que le dan los indios a los hombres blancos que buscan oro en Alaska. Su

\footnotetext{
${ }^{22}$ Haley, James L. Wolf. The lives of Jack London. New York: Basic Books, 2010.

${ }^{23}$ The portable Jack London, edited by Earle Labor. New York: Penguin Books, 1994.
} 
espíritu temerario y de experto explorador lleva, dice el narrador, "las marcas de haber nacido en la frontera y de una vida en la frontera". Cogote Mackenzie se adentra en la región del Yukon donde habitan los Sticks, los Hijos del Cuervo, una peligrosa tribu de nativos. Lo impulsa la necesidad de mujer, de aparejarse en sentido animal, (según la voz del narrador tiene "hambre" de mujer y "le ha caído encima la enfermedad del deseo"). Encaprichado con Zarinska, la hija del Jefe de la tribu, Cogote matiza su comportamiento animal con regalos y obsequios, hasta que el padre acepta cedérsela. Pero el Chaman y los jóvenes de la tribu se oponen a la unión por razones de sobrevivencia. A partir de allí, y paso a paso, se desarrolla un conflicto, la disputa entre el Hijo del Lobo que busca procrear y satisfacer su instinto, y los miembros de la tribu que luchan por preservar la territorialidad y asegurar la continuidad del grupo.

Las referencias del narrador a los personajes se van progresivamente animalizando: Cogote Mackenzie será el Hijo del Lobo, o simplemente, el lobo; de Zarinska señala que está capacitada para convertirse en "madre de los lobos" y los jóvenes de la tribu serán el Oso, el Zorro o los hijos del Cuervo. Hombres-animales que pelean encarnizadamente, pedernal o cuchillo en mano, luchando -como dice el narrador- "por la presa". No hay fronteras entre la condición humana y la condición animal. Es también una disputa que involucra distintas temporalidades; de pronto una escena es perfilada en la época de las cavernas, y cuando se produce el encuentro a solas entre el Hijo del Lobo y Zarinska, el narrador dice que fue un encuentro entre "la edad de la piedra y la edad del metal" (referencia en la que subyace el darwinismo social y la superioridad de la raza blanca). Los instintos y lo atávico motivan la acción de los personajes y su progresiva animalización, perspectiva que es manejada con gradualidad y sutileza por la voz narrativa. El relato concluye cuando el Hijo del Lobo mata al Chaman y calma al Zorro dejándole algunos tacos de tabaco, antes de irse con Zarinska.

"Batard" es un relato estructurado en torno al odio ancestral entre Black Leclerc, aventurero y explorador del Yukon, y el perro Batard, un odio gratuito que está signado en las denominaciones de origen de ambos protagonistas ("Black": negro y "Batard": demonio, en francés). El perro es hijo de una perra Husky (pendenciera y obscena) y de un gran lobo gris. Desde cachorro ataca a Leclerc porque sí o porque no (le entierra los colmillos en la mano) y éste a su vez casi lo estrangula, 
apretándole la garganta. "En los progenitores de Batard -acota el narrador- había mucha fuerza y mucha maldad, y él las había heredado con su carne y su sangre”. Desde pequeño Batard es más lobo que perro. Leclerc, por su parte, odiaba al perro con "su inteligencia y conocimiento, mientras el pobre cachorrillo de largas patas lo hacía a ciegas, instintivamente, sin método ni razón”. "El odio que sentían los unía de una forma que el amor nunca conseguiría". En este nivel de agresión mutua recorren durante 5 ańos los cinco mil kilómetros que van desde el delta del Yukon hasta el lago Great Slave. En el recorrido se va produciendo una transformación paulatina: el perro-lobo se va empoderando de una inteligencia rudimentaria desde la cual canaliza su saña, mientras que Leclerc empieza a actuar solo motivado por el instinto, y sin ningún tipo de consideración ética, llegando incluso a practicar la tortura sobre el perro. En una oportunidad, el explorador yace dormido entre pieles y Batard lo ataca al cogote, pero "como (Leclerc) tenía todo el instinto de un animal", "la bestia que había en él estaba alerta y rabiosa" "Leclerc despertó totalmente despejado y agarró la tráquea de Batard", pero en la agresión y defensa de uno y otro opera también lo atávico: "miles de antepasados de Batard -dice el narrador- se habían aferrado a las gargantas de innumerables alces y caribús y los habían derribado. Y él tenía la sabiduría de todos esos antepasados”.

Batard se hominiza y Leclerc se animaliza. La transformación del explorador del Yukon involucra una vivencia de plenitud, que se da también en otros textos de London: en su animalización Leclerc está siendo partícipe de la vida desnuda, de esa vida vegetativa desprovista de toda cualificación -la nuda vida de Agamben- ${ }^{24}$, pero en esta ocasión fuera de las tenazas del Estado. Instalado en la intimidad del personaje, el narrador refiere la adrenalina que experimenta Leclerc: "sentía que se había introducido en la misma esencia de la vida: esa esencia invencible que impele al halcón a través de los cielos como un rayo emplumado, que guía al gran pato gris por los parajes, que impulsa al salmón preńado a lo largo del impetuoso caudal del Yukon. En tales ocasiones (Leclerc) se sentía impulsado a expresar la invencible esencia de la vida... con sus limitadas fuerzas se sentía capaz de cualquier cosa, y desafiaba a cuanto existe, había existido y estaba por venir”. Cuando Buck, el perro protagonista de The call of the wild, se asume como lobo luego de recorrer el itinerario que va desde el jardín de una casa californiana a los parajes desérticos de

\footnotetext{
${ }^{24}$ Agamben, Giorgio. Homo Sacer. El poder soberano y la nuda vida. Valencia. España: Pretextos, 1998. Es la vida desprovista de toda cualificación, es la vida puramente biológica y orgánica, la que tiene en común la vida humana con la de un caracol o una planta.
} 
Alaska, cuando corre "al frente de la jauría, persiguiendo la presa salvaje ... para matar con sus propios dientes y bañar su hocico en sangre caliente", el narrador comenta: hay "un éxtasis que señala la cúspide de la vida, más allá de la cual la vida no puede elevarse...Ese éxtasis, ese olvido de la existencia, alcanza al artista, convirtiéndolo en una llama de pasión; alcanza al soldado, que en el ardor de la batalla ni pide ni da tregua, y alcanzó a Buck, que corría al frente de la jauría, lanzando el atávico grito de los lobos y pugnando por alcanzar el viviente manjar que huía a la luz de la luna". Hay incluso en esta novela un fragmento que se condice perfectamente con lo que plantea Ortega sobre el cazador: "Toda esa conmoción de los viejos instintos, que de vez en cuando lleva a los hombres a abandonar las ciudades bulliciosas por selvas y praderas, para matar con proyectiles de prodigioso alcance, y la concupiscencia de la sangre y la alegría de matar, todo eso dominaba ahora a Buck". En la vida desnuda, en la vida meramente biológica y orgánica, en "las vacaciones de la humanidad" las fronteras entre lo humano y lo animal se diluyen y se tornan gozosamente ambivalentes.

Los otros perros del trineo quieren dar cuenta de Batard, que en su condición de hijo de lobo resultaba ajeno al grupo (el instinto de agresión xenofóbico) pero Leclerc lo impide, quiere reservarse para sí el placer de matarlo. La imposibilidad de liquidarlo ha acrecentado su odio hacia el perro. La tensión se mantiene hasta el final del relato, hasta que el azar involucra a Leclerc en el crimen de Timothy Brown. Condenado a la horca lo instalan con la soga al cuello sobre un cajón. Justo cuando llegaba un testigo que podía salvarlo, Batard, que ahora piensa y no es mero instinto, se escurre y en un descuido bota el cajón y Leclerc muere ahorcado. También sucumbe Batard cuando Webster Shaw y Slackwater le disparan entre "los ojos ardientes", el perro queda inerte pero con las "mandíbulas apretadas", mueca final que apunta a un escenario en que los instintos, lo atávico y la inteligencia orientan las acciones de protagonista y antagonista en una lucha milenaria por la territorialidad y la subsistencia.

El Yukon es un espacio inhóspito, un drama permanente en que el peligro y las condiciones climáticas hermanan la vida y la muerte. La subsistencia está siempre al borde del precipicio. Ese borde es el que transitan en "The love of life" el protagonista y un lobo. El relato se abre con dos hombres bajando débiles y extenuados por la ribera, uno de ellos se tuerce el tobillo y percibe cómo su 
compañero Bill sigue adelante y se aleja cojeando, hasta perderse en la lontananza. La narración se instala progresivamente en el punto de vista y conciencia del rezagado ("cuyos ojos", acota el narrador, "parecían los de un ciervo herido"). El lector asiste a un deterioro progresivo y a la condición cada vez más exhausta del herido (pies llagados, carne desollada, alucinaciones, cuando ya no puede caminar se arrastra), una condición que contrasta con la vitalidad del verano ártico, con manadas de Caribús que se desplazan al trote, con lobos aullando en las noches, con nieve y vientos helados. Lo aqueja sobre todo el más primario y compartido de los instintos, aquel que emerge de las entrańas del organismo: el hambre. Un hambre que lo lleva a alimentarse de muzgos, de juncos o a chupar y roer con desesperación los huesos de una cría de Caribú después que ha sido despedazada por una manada de lobos.

De pronto, en la mitad del relato el protagonista escucha un estertor ahogado, una tos próxima, es un lobo herido que lo sigue a un par de metros, que pasa la lengua sobre sus huellas de sangre y que tiene en la mirada la esperanza de que el hombre muera para saciar su hambre. La tensión entre los dos heridos y exhaustos por el hambre se registra en los ojos, en las miradas desoladas, en la pugna que se arrastra. Es el instinto desesperado de ambos por sobrevivir, la lucha empedernida contra la propia falta de fuerza y la proximidad de la muerte. "La poca vida que quedaba en el hombre -nos dice el narrador- lo empujaba a seguir avanzando". Los olores y resoplidos del lobo le llegan a la oreja, se aproximan tanto que acaban enfrentándose: "entonces comenzó la más espantosa lucha por la vida que puede concebir la mente humana: un hombre enfermo y agotado que apenas podía andar, contra un lobo extenuado que apenas se sostenía en sus patas". Los dos moribundos se trenzan y revuelcan, el hombre le muerde la garganta al lobo y bebe su sangre (actuando como una fiera), el lobo se desploma y el hombre queda encima con todo su peso. Luego se desplaza "ciego e inconsciente, reptando por el suelo como un gusano monstruoso", avanza apenas seis metros en una hora. Tres semanas después, el viajero del Yukon está sentado en una litera del ballenero Bedford, en viaje a San Francisco. En la escena final esconde su porción de galletas debajo del colchón, obsesionado por el miedo al espectro del hambre.

Una vez más, los límites entre la condición humana y la condición animal se diluyen, la soberbia de la especie desaparece. Las sinuosidades de la vida vegetativa 
y la lucha por sobrevivir al borde del precipicio han sido recorridas con una gradualidad prolija en detalles, con una destreza narrativa que es una trasposición a la literatura de las tensiones de la evolución y de la biología, registradas con un microscopio del siglo XIX. No es casual que a un ateo y materialista, como lo fue Lenin, le haya entusiasmado este cuento en sus días finales.

\section{NOVELAS DE IDA Y VUELTA}

En la perspectiva darwinista, la evolución es un avance y un retroceso, un presente y un pasado, lo que fue en illo tempore seguirá siendo. Los lobos serán potencialmente perros, y los perros, en la medida que reaparecen instintos ancestrales, lobos. Este es el pensar literario que subyace a las dos novelas más famosas de Jack London: The call of the wild (1903) y White fang (1906). Pensamiento que el autor aplica también a los seres humanos y a la dialéctica entre "primitivos" y "civilizados", en una cosmovisión que se aproxima a la famosa frase de Walter Benjamin: "Todo acto de civilización envuelve al mismo tiempo un acto de barbarie”.

El llamado de la selva y Colmillo Blanco son dos novelas simétricas. La primera relata el itinerario de Buck, perro mezcla de San Bernardo y pastor alemán, desde la casa de un Juez de California, a la inhóspita zona del Yukon como perro de trineo, recorrido en que por adaptación al medio, despertar del atavismo y necesidades de sobrevivir, asume su ancestro de lobo, y termina sus días como líder de una manada corriendo como un demonio feliz por las nevadas praderas del ártico, a la luz de la luna. Es el tránsito del jardín a la selva, del ladrido al aullido. La segunda, en cambio, recorre el mismo camino pero a la inversa. Relata el tránsito de Colmillo Blanco, hijo de un lobo y de una perra mestiza, desde sus correrías por el ártico helado a perro domesticado, desde el aullido al ladrido, desde la selva al jardín de una casa solariega en el sur de California. Ambas novelas están narradas desde un punto de vista que es externo, omnisciente y a la vez interno, apegado a los pensamientos y emociones de los dos perros-lobos, de Buck y Colmillo Blanco. Esta modalidad permite por una parte un narrador personal que con un fuerte tinte darwiniano va dando cuenta del itinerario y las transformaciones, $y$, también, una focalización en los animales, que a menudo se ven conflictuados entre la regalía de la vida doméstica y el calor del hogar y por otro lado la ferocidad, la astucia y el éxtasis de la vida ancestral. 
En La llamada de la selva, Buck es robado por el jardinero de la casa del Juez Californiano, y vendido como perro de trineo a los buscadores de oro en la zona del Yukon. Ya en medio de la nieve tiene temor de caer en una trampa, ocasión en que el narrador acota: "era un indicio que se estaba remontando... a la vida de sus antepasados, ya que por ser perro civilizado no conocía trampa alguna y por lo tanto no podía temerlas"25. Gracias a la verosimilitud del relato, el lector asiste (sin que decaiga el interés) al proceso de adaptación tanto en sus pensamientos como en su físico al nuevo entorno; por este motivo no resultan contraproducentes los párrafos netamente darwinianos del tipo: Buck "demostró su capacidad de acomodarse a los cambios, condición cuya falta hubiérale ocasionado una rápida y terrible muerte. Demostró además la declinación, o mejor aún la ruina de su moralidad, algo superfluo y una desventaja en la despiadada lucha por la existencia"26. Hay una escena en que Buck en un campamento, a la orilla del fuego, al ver al cocinero tiene la visión del hombre velludo de Neanderthal, y experimenta una ensońación con el hombre prehistórico, lo que apunta a la idea darwiniana de que la evolución humana y animal han recorridos procesos similares y paralelos.

Acomodándose a la "ley del garrote y del colmillo", Buck, va perdiendo la delicadeza de su vida anterior. Luego de una serie de alternativas (maltrato de algunos amos, cariño de otro, disputa con Spitz y los perros Husky que lo perciben como un afuerino) huye para vivir en el bosque, dedicándose a cazar cervatillos con la paciencia obstinada de la araña que permanece inmóvil en su tela durante horas. En este proceso, se le fortalecen los músculos y agudiza el olfato; entregado a sus instintos de ancestro experimenta el éxtasis de una nueva vida, hermanándose con otros lobos: "cuando en las noches serenas y frías dirigía el hocico hacia arriba y aullaba como un lobo, eran sus antepasados muertos ya y convertidos en polvo, los que dirigían el hocico a las estrellas y aullaban a través de los siglos"27.

Concebida por London como una antítesis y complemento de su novela anterior, Colmillo Blanco se abre con una escena magistral en términos descriptivos: al anochecer dos hombres avanzan penosamente por la nieve arrastrando un ataúd a 50 grados bajo cero; tiran el trineo una hilera de perros lobos, asediados por una manada de lobos hambrientos y furiosos, cuyas costillas semejan un enrejado,

\footnotetext{
${ }^{25}$ London, Jack. La llamada de la selva. Santiago de Chile: Andrés Bello, 2006: 29.

${ }^{26}$ London, Jack. La llamada de la selva, op. cit., 33.

${ }^{27}$ London, Jack. La llamada de la selva, op.cit., 35.
} 
la amenaza y el miedo son crecientes, perros y hombres serán alimentos para la manada. Una loba mestiza que formaba parte de la manada da a luz a Colmillo Blanco. El cachorro es un lobezno con huellas de ancestro perruno; el narrador, en una suerte de bildungsroman relata su crecimiento y desarrollo. En contacto con los miembros de una tribu indígena primero, y luego con exploradores, el lector asiste al paulatino proceso de aprendizaje y domesticación de Colmillo Blanco, que al amparo de distintos amos "engordaba y la vida le parecía próspera y saludable". Pero también tendrá, como Buck, sus dudas, sobre todo cuando lo llevan a California. A veces echa de menos la nieve: "todavía le quedaban -nos dice el narrador- vestigios de cierta ferocidad como si la vida salvaje se prolongara en su interior y el lobo no estuviera en él más que dormido" ${ }^{28}$. Sin embargo, en un nuevo ambiente ese pasado va quedando atrás: en la casa solariega del Juez Scott, se torna cada vez más leal y servicial, salvando incluso a su amo de un asalto. Se aparea también con una perra Collie y nacen perritos. Colmillo Blanco transita desde el ártico helado y el mundo primitivo al mundo de la seguridad domestica, desde una tribu indígena y algunos amos despiadados a una mansión del sur de California, desde la selva al jardín. Así se cierra el círculo en una novela que fue concebida por su autor como una antítesis y complemento de su novela anterior.

\section{LECTURAS}

Ambas novelas han sido leídas como una alegoría de los seres humanos en su lucha por sobrevivir y adaptarse a la modernidad, interpretación que no nos convence, en primer lugar porque el foco narrativo está puesto expresamente en los perros y lobos. Se focaliza en los animales y en sus procesos de adaptación y no en los diferentes amos, pero sobre todo esta lectura no nos convence porque la alegoría es un género en que personajes, animales, espacio y acción no sólo significan por sí mismos, sino que apelan a un segundo orden correlativo, orden que debido al realismo y potencia descriptiva de la novela de London sencillamente no existe. Los lobos y los perros son lo que son, y no figuras alegóricas o metafóricas. Lo que sí hay -una vez más- son perros y lobos en un escenario en que se tienden a esfumar las fronteras entre animales humanos y no humanos, en que desaparece o se matiza la soberbia humana de pensarse como medida de todo lo que existe, en

\footnotetext{
${ }^{28}$ London, Jack. Colmillo Blanco. Santiago de Chile: Andrés Bello, 2010: 308. (Traducción cotejada con Jack London, The call of the wild, White Dang and to build a fire. New York: The modern Library, 1998).
} 
que se erosiona el antropocentrismo: animales y hombres son pares: todos luchan por sobrevivir y adaptarse a un ambiente hostil, condicionados por sus instintos y por la herencia. London construye imaginarios que dignifican tanto a los lobos como a los perros, a los que corren desbocados en las praderas nevadas y a los que dormitan plácidamente junto a la chimenea, todos tienen instintos, inteligencia, memoria, sentimientos y personalidad. Dignifica también a unos pocos -muy pocos- seres humanos de buen corazón, aquellos que son capaces de una tenencia responsable. La voz narrativa resalta además a un actor que describe y vivifica con prolijidad, un protagonista que en alguna medida incide tanto en lo que sucede como en lo que no sucede: la naturaleza. Por todo ello puede afirmarse que Jack London es un hito en la presencia del mundo animal y natural en el imaginario americano, en su presencia como mito, como una alteridad significativa, como compañía y amistad, y a veces también, tal como sucede entre los seres humanos, como rival y enemigo.

\section{FUNDAMENTALISMO BIOLOGISTA}

Como todos los autores, Jack London escribe al interior de una burbuja epocal, marcada por un clima intelectual e ideas-fuerza predominantes que permean la producción artística y simbólica. Se trata no solo de ideas que se encuentran en los libros (algunos de los cuales llevó al Yukon); son también ideas operantes en la vida social y cotidiana, ideas que participan del paradigma de lo obvio, que a pesar de estar allí no se ven. Al interior de la burbuja, los autores son en alguna medida como peces en el mar: nadan sin tener conciencia en donde están nadando. La perspectiva biologicista y darwiniana y el determinismo positivista son los esqueletos de esta burbuja, en la que se aloja también el naturalismo literario de Zola y su propósito de cientificismo literario: la idea de que los animales y los humanos están determinados por el entorno, la herencia y la lucha por prevalecer. Son ideas que van a dar lugar a estrategias compositivas de personajes que van desde un afuera que determina el adentro, desde el entorno y lo biológico hereditario a lo sicológico. Naturalismo literario que se dio en Francia hacia 1870 y en Estados Unidos hacia fines del siglo XIX y comienzos del XX, con autores como Theodore Dreiser, Stephan Crane, Frank Norris y O. Henry. Ahora bien, lo significativo es que a pesar de las restricciones (y también de las posibilidades) que implica estar al interior de una burbuja sin tener conciencia de ello, hay escritores, y es el 
caso de London, que sobrepasan las determinaciones ideológicas y conceptuales de la misma, y devienen clásicos. La burbuja deja de ser un referente o permanece oculta, en la medida que la obra de London adquiere verosimilitud literaria y consistencia por sí misma, de modo que todo lo que se relata en ella está vivo, moviéndose, en trance de ocurrir gracias a la magia de las palabras y de la ficción. Mientras las teorías y las ideas zanjan sus argumentos con la universalidad del concepto, la ficción se nutre de pormenores y particularidades. El pensar literario pertenece al mundo de la vida. En la mente de los lectores, sean niños, adolescentes o adultos, las aventuras y los hechos a los que da vida Jack London ocurrirán probablemente sin ajarse- una y otra vez, hoy, mañana y siempre.

Reconociendo la calidad estética y la autonomía de su obra, es legítimo, sin embargo, mirar y pinchar esa burbuja biologista, ponerla en dificultad desde una mirada externa. $\mathrm{O}$ si se quiere, examinar también algunos aspectos del pensamiento que subyace a la obra del autor. London fue durante toda su vida un defensor y un pionero del derecho de los animales; así lo señala en el prólogo de una de sus últimas novelas. En Michael, brother of Jerry, (obra póstuma traducida al español como Miguel, perro de (irco $)^{29}$, se relata las aventuras polinésicas de Miguel, un perrito fox terrier que pasa por distintos amos y goletas para terminar siendo vendido a un circo. El narrador lo describe como un can que sabía lo que eran el afecto y el odio, la noción de sí mismo, la pena y la alegría...también poseía, dice: “esos tres atributos del espíritu humano, que se cuentan entre los principales: memoria, inteligencia y voluntad". En el circo, el fox terrier es testigo de las torturas a que son sometidos osos, leones y otros animales, los que con fines pecuniarios son atormentados por propietarios y domadores. London, en el prólogo, luego de enumerar algunas de las miserias humanas que ha conocido, señala que en su vida nada "le ha indignado tanto como los circos y esos pobres animales indefensos... que ejercitan sus habilidades aprendidas a fuerza de martirios".

Junto con esta defensa de los animales, amparada en cierta medida por las ideas darwinistas, hay varios pasajes en la obra de London que evidencian su creencia en la superioridad de ciertas razas (la blanca, sobre todo) con respecto a otras, pensamiento afín a un darwinismo social. La idea de la selección natural aplicada

${ }^{29}$ Escrita en 1915, un año antes de su muerte, fue publicada en 1917 por McMillan en Nueva York y traducida al español de la edición francesa Miguel, perro de circo. Buenos Aires: Biblioteca, 1952: 41. 
a las razas y a la sociedad implicaba una suerte de racismo, en la medida que afirmaba que existían razas superiores, más avanzadas y evolucionadas que otras. Como muchos de los hombres cultos e ilustrados del siglo XIX, London fue partidario -como también lo fue Darwin- de la eugenesia, disciplina médica que se proponía la mejora biológica de la especie, y que estaba avalada en teorías raciales de corte eurocéntrico. Estas ideas contribuyeron a fines del siglo XIX a los zoológicos humanos en Berlín, París y Zurich, a los que se llevaron por la fuerza etnias fueguinas (kaweskar y otras), exhibiéndolas comercialmente como curiosidades antropológicas. Indígenas que eran expuestos en jaulas, a veces con el patrocinio de prestigiosas sociedades científicas europeas, habitantes nativos de Chile que tuvieron en su mayoría un destino trágico.

La contradicción entre la defensa de animales con rasgos humanos y la denostación de seres humanos por poseer ciertos rasgos raciales se advierte también en algunos de sus obras. En Miguel perro de circo, por ejemplo, el narrador omnisciente traspasa al perro pensamientos ofensivos sobre Kwaque, un muchacho de raza negra que encuentra en una de las goletas "Uf... ese Kwaque era negro", piensa el perro, ariscando la nariz. Pero es sobre todo en una serie de reportajes que realizó en 1914, a propósito de la presencia en Veracruz de la fuerza naval norteamericana y de la revolución mexicana en curso, donde se hacen evidentes sus prejuicios respecto a las razas no blancas. London estuvo varios meses en Veracruz y Tampico comisionado por las revista Colliers Magazine, en la que publicó cinco artículos. En ellos se muestra tácitamente partidario de la doctrina Monroe, glorifica a los marines norteamericanos y de los peones mexicanos enrolados en la Revolución dice que son "estúpidos, salvajes y fatalistas". Les atribuye un salvajismo atávico y señala también que los sectores medios y mestizos de México difícilmente pueden ser considerados "civilizados". Los cinco artículos están enmarcados en la dicotomía civilizados (los norteamericanos) y bárbaros (la mayoría de los mexicanos). "Hay que salvar a México de sí mismo", dice, y plantea como posible solución el anexamiento de México por Estados Unidos, cuestión que es favorecida -señala- por un sector de la población mexicana. De Victoriano Huerta dice que su gran error fue no haber fusilado a Emiliano Zapata y a Francisco Villa. El darwinismo social que postulaba los principios de la biología y de la evolución para las colectividades sociales está en el trasfondo de estas opiniones ${ }^{30}$.

${ }^{30}$ Cabe señalar que esta postura de 1914 contraviene la que tuvo en 1911, cuando participo en un mitin celebrado en Los Angeles, a favor de los magonistas y de su ocupación de Mexicali en Baja California. 
El fundamentalismo biológico también se hace presente en la concepción de la agresividad y la violencia. En un cuento como "Batard" la violencia como conducta gratuita está representada como propia de los hombres y de los animales, en tanto responde a un instinto de agresividad que unos y otros comparten. Se trata de una postura que de alguna manera le confiere impunidad a la violencia y la justifica desde la biología animal. La violencia se manifiesta y proviene de un fondo animal existente en el hombre, de tal manera que los seres humanos son crueles y violentos por esta supuesta animalidad pero no en tanto que hombres ${ }^{31}$. Las mujeres son entes reproductores. $\mathrm{O}$ como dice uno de los cuentos de London: una "presa" que se disputan dos animales humanos. Se trata de un pensamiento literario que desde un integrismo biologista prescinde del enculturamiento, de ese proceso mediante el cual la especie humana se ha dado una ética social que le impide abandonarse ciegamente a los instintos, un enculturamiento que la habría distanciado de la mera evolución biológica.

Estas reflexiones, como lo hemos señalado, en nada desmerecen los logros estéticos de las novelas y cuentos perrunos de Jack London. Precisamente, aun dentro de la burbuja, son posibles creaciones imperecederas, en que el autor asume una mirada más humilde y solidaria respecto a las relaciones del hombre con el mundo animal y la naturaleza. La verdad de la literatura y del pensar literario responde a una lógica distinta a la de la verdad del pensamiento racional o filosófico, y no necesariamente debe coincidir con lo "políticamente correcto". Por otro lado, vivimos en una época en que la tentación del fundamentalismo biologista puede reaparecer -o esta reapareciendo- en la medida que ya es posible y comercializable la autoproducción humana y animal, gracias al manejo de técnicas que permiten recrear o corregir las especies a través de la manipulación del genoma y de los códigos genéticos. Ideas y prácticas riesgosas, que en el futuro tal vez otorgarán un trasfondo de verosimilitud a excelentes novelas de ciencia ficción, pero que no por ello dejaran de ser ideas con proyecciones inesperadas.

Estamos conscientes que al mirar y pinchar desde un afuera a la burbuja biologista (determinista y darwiniana) en que se sitúa la obra de London, lo hacemos con una mirada que a su vez está instalada en otra burbuja (la de la diversidad social y cultural emancipatoria), burbuja que seguramente también podrá ser pinchada y desinflada desde un afuera en cien ańos más.

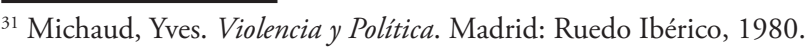




\section{REFERENCIAS}

Agamben, Giorgio. Homo Sacer. El poder soberano y la nuda vida. Valencia. España: Pretextos, 1998.

Dancer, Andrea. "Ernest Thompson Seton and the Canadian Wilderness Imaginary: the realistic Illusion of nature". En Kamila Vrakova y Christopher Koy (eds.). Dream, Imagination and Reality in Literature, en South Bohemian Anglo-American Studies 1. Checoslovaquia, 2006.

Earle Labor (ed.). The portable Jack London. New York: Penguin Books, 1994.

Haley, James L. Wolf. The lives of Jack London. New York: Basic Books, 2010.

Jastrow, Robert. Charles Darwin: Textos fundamentales. Barcelona: Altaya, 1993.

Jay Gould, Stephen. Ever Since Darwin: Reflections in Natural History. Nueva York: Norton \& Company, 1977.

London, Jack. Colmillo Blanco. Santiago de Chile: Andrés Bello, 2010.

La llamada de la selva. Santiago de Chile: Andrés Bello, 2006.

Miguel, perro de circo. Buenos Aires: Biblioteca, 1952.

Revolution and Other Essays. New York: McMillan, 1909.

Lorenz, Karl. Sobre la agresión, el pretendido mal. Madrid: Siglo XXI, 1971.

Loren, Konrad. Cuando el hombre encontró al perro. Barcelona: Tusquets, 1875.

Lutt, Ralh H. The Nature Fakers: wildlife, Science \& sentiment. Virginia: University Press, 2001. 
Malson, Lucien y Itar, Jean M. G. Les enfants sauvages: mythe et réalité. Paris:Union générale diéditions, 1964; Candland, Douglas K. Feral children and clever animals: Reflections on Human Nature. London: Oxford University Press, 1993.

Michaud, Yves. Violencia y Política. Madrid: Ruedo Ibérico, 1980.

Newton, Michael. Savage Girls and Wild Boys: a history of feral children. Nueva York: Picador, 2004.

Ortega y Gasset, José. Sobre la caza, los toros y el toreo. Madrid: Alianza, 1960.

Ortega y Gasset, José. Veinte años de caza mayor. Por el Conde de Yebes. Madrid: Espasa Calpe, 1943.

Troncoso, Julieta. "El concepto de Comportamiento Aprendido". En Enrique Zerda (ed.). Bases biológicas del Comportamiento Animal y Humano. Colombia: Editorial Universidad Nacional de Colombia (2010): 69-79.

Zerda, Enrique (ed.). Bases biológicas del Comportamiento Animal y Humano. Bogotá: Editorial Universidad Nacional de Colombia, 2010. 